\title{
Ageing and Health Status of Older People in Bangladesh
}

\author{
Md. Shohel Rana*, Najma Begum, Shankar Barai, Sabbir Hussain Shanta, \\ Md. Alauddin Rasel, Salma Akter Tania, Farhana Afsar
}

Department of Statistics, Noakhali Science and Technology University, Noakhali, Bangladesh

Email address:

rana.nstu83@gmail.com (Md. S. Rana)

${ }^{*}$ Corresponding author

\section{To cite this article:}

Md. Shohel Rana, Najma Begum, Shankar Barai, Sabbir Hussain Shanta, Md. Alauddin Rasel, Salma Akter Tania, Farhana Afsar. Ageing and Health Status of Older People in Bangladesh. Biomedical Statistics and Informatics. Vol. 5, No. 2, 2020, pp. 39-46.

doi: $10.11648 /$ j.bsi.20200502.11

Received: March 9, 2020; Accepted: April 3, 2020; Published: June 4, 2020

\begin{abstract}
Ageing is an ongoing physiological process. As mortality declining and improving public health interventions which result population ageing. The present study is an attempt to assess the health status of ageing people living in Bangladesh. We found most of the ageing people's family expenditure are bear by their son which is $78.9 \%$. We also found that $52.6 \%$ ageing people's health are care by son which is maximum. Most of the older people's $(60.2 \%)$ treatment cost below 2000 taka. According to the study there is $33.3 \%$ of ageing people have the disease of diabetics, $20.5 \%$ have the problem of blood pressure and $19.9 \%$ have heart disease. We observe that $70.8 \%$ of ageing people monthly visit to doctor for treatment. However, the satisfaction level of treatment is positively correlated and significant with who bear the family expenditure. There is a weak positive relationship between the satisfaction level of treatment and who health care most but it was insignificant. We also found that there is a weak positive relationship between the satisfaction level of treatment and how frequently the ageing people visit to doctor for treatment and it was insignificant. Logistic result indicates that if we increase one unit of family expenditure bear (son), health care most (son) and visiting doctor (daily) then the satisfaction level (yes) will increase respectively $0.694,0.018$ and 0.116 unit.
\end{abstract}

Keywords: Ageing, Health, Logistic Regression, Bangladesh

\section{Introduction}

Like the global pattern, the number and rate of elderly population of Bangladesh is increasing and expected to increase more in the future years. It is projected that by 2025, the population of elderly people will exceed 17 million [1]. Compared with high-income countries, population of ageing people will take place over a short period of time in Bangladesh and the country will have much less time to deal with its consequences. So we can easily assume that if the problems of the elderly is not solved it will add a great dimension of hindrance for the country. A study shows that $80 \%$ respondents suffered from chronic diseases. Arthritis and diabetes was more common. $50 \%$ of respondents told that their appetite had reduced partially. Nutritional status of the study subjects represents surprising results. Underweight, normal, overweight and obese were $24 \%, 32 \%, 32 \%$ and $12 \%$ of respondents [2].
The percentage of men is slightly higher than that of women, which represents $43.6 \%$. In terms of age, all of them are older adults aged between 60 and 70 , with $43 \%$ of the sample being between 60 and 70 years old, compared to57\% between 70 and 87 years old. The socioeconomic level of the participants is medium low, with an average income ranging from 500 to $600 €$ per month, although they are within the national average [3]. The impact of living alone varies by cultural, demographic, and policy contexts. The papers identify groups that are potentially vulnerable to social isolation and financial distress and challenge the generally negative stereotypes of the OPH living arrangement [4]. Olli Nummela (2008) examined associations between self-rated health and combinations of social participation and trust among ageing people in three living areas of Finland $(\mathrm{N}=2815,66 \%$ response rate $)$ [11]. 
Su Hyun Kim (2008) explore the influence of expectations regarding ageing on physical and mental health status, and to examine the mediating effects of health-promoting behaviour on the relationship between these expectations and physical and mental health [12]. Meindert Haveman (2011) showed that more than $60 \%$ of older adults had a sedentary lifestyle. Cataract, hearing disorder, diabetes, hypertension, osteoarthritis/arthrosis, and osteoporosis were positively associated with advancing age; allergies and epilepsy, negatively associated [13]. Nummela O., (2008) found the association of leisure activities and good selfrated health may differ for genders due to their nature or meaning. Partial support was found for the assumption that leisure activities go together with better self-rated health among ageing people [14].

Bangladesh one of the most populous and poorest countries in the world (where $29 \%$ of the population lives on less than US \$ 1.00 a day) [5]. According to World Population Ageing Report 2013, World's population 60+, $65+$ and $80+$ were 840628,570459 and 120199 respectively. Moreover these numbers were 468549, 307699 and 57576in Asia, 60033, 38513 and 5248in Africa, 169874, 125152 and 33239 in Europe [6]. In Bangladesh, the National census between 1974 and 2011 the growth of elderly people is gradually increasing. In 1974, the populations between 60-64 years were 1682629 and in 2011 the numbers were 3218974 . At the same way aged between 65-69 years population were 735255 and 1998760in 1974 and 2011 respectively. In the same period of time populations of elderly over 70 years were 1639056 to 1998760 .

Report shows that percentage of elderly people age between $60-64,65-69,70-75$ and over 70 years were $37 \%$, $21 \% 20 \%$ and $22 \%$ respectively [7]. Though, the number rural elderly in each of the divisions is increasing over time, the rate of increase in other than rural elderly is higher than the rate for the rural elderly. For instance, in Khulna division, the rural elderly from 2015 to 2020 is increased by 29985 whereas this number for other than rural elderly is 105609. Moreover, for Khulna division, the relative rate of increment in rural elderly from year 2015 to 2020 is 3.69 percent which would be approximately 16.94 percent from year 2020 to 2025 . In contrast, these quantities for other than rural elderly are approximately 14 percent and 28.64 percent respectively [8]. According to Mini Nutritional assessment (MNA) score, result showed that 26\% prevalence of protein energy malnutrition and $62 \%$ to be at risk of malnutrition were seen in rural Bangladesh [9]. Compared with high-income countries, population ageing will take place over a shorter period of time in Bangladesh and the country will have much less time to deal with it's consequences [10]. Ahmed Mohammad Munsur (2010) have attempted to observe the socio-economic backdrops, living arrangements, health status and abuse of the older women and the findings of the study should get due attention to provide secured later life of the elder especially female elderly in Bangladesh [15].

\section{Objectives}

The main objectives of the study are:

i. To find the current status of ageing people of Bangladesh.

ii. To find the root causes of vulnerability of elderly people in Bangladesh.

iii. To explore the household structure to assess the family structure through age distribution of the family members and social positioning of the household with elderly population.

iv. To find the emerging issues and challenges of elderly people of Bangladesh.

v. To know the awareness about the elder people in the whole world.

\section{Limitation}

The major limitation is that maximum respondents are illiterate. That's why they could not give us the exact information. Many of them give us inaccurate information. We collect information from 171 respondents all over the country. We cannot collect more than 171 because of limitation of time, transport cost and we have less manpower to collect data.

\section{Methodology}

This is a case and field study research. A well-structured questionnaire has been developed after the intensive review of the literature and practical experience. A face-to-face survey was conducted among the ageing people of different district of Bangladesh. The survey was administered among 171 elderly people in 2019 via questionnaire using a short version of the expectation regarding some aging questions. In accession to this, we will apply statistical methods to ascertain the health status and overall social-life of ageing people. We have used different statistical methods such as frequency distribution, correlation, chi-square test and logistic regression to analyze data. The result of this entire paper is computed by using IBM SPSS 15.0.

\section{Result and Discussion}

Table 1. Family expenditure bearing of older people.

\begin{tabular}{llll}
\hline Variable & Frequency & Percent & Cumulative Percent \\
\hline Son & 135 & 78.9 & 78.9 \\
Daughter & 13 & 7.6 & 86.5 \\
Other & 23 & 13.5 & 100 \\
Total & 171 & 100 & - \\
\hline
\end{tabular}

Among 171 respondents, 78.9\% ageing people's family expenditure are bear by their son, 7.6\% ageing people depends on their daughters to bear their family expenditure and $13.5 \%$ ageing people's family expenditure are bear by others. So we can say that majority of the ageing people's family expenditure are bear by their son. 


\section{Family expenditure bear}

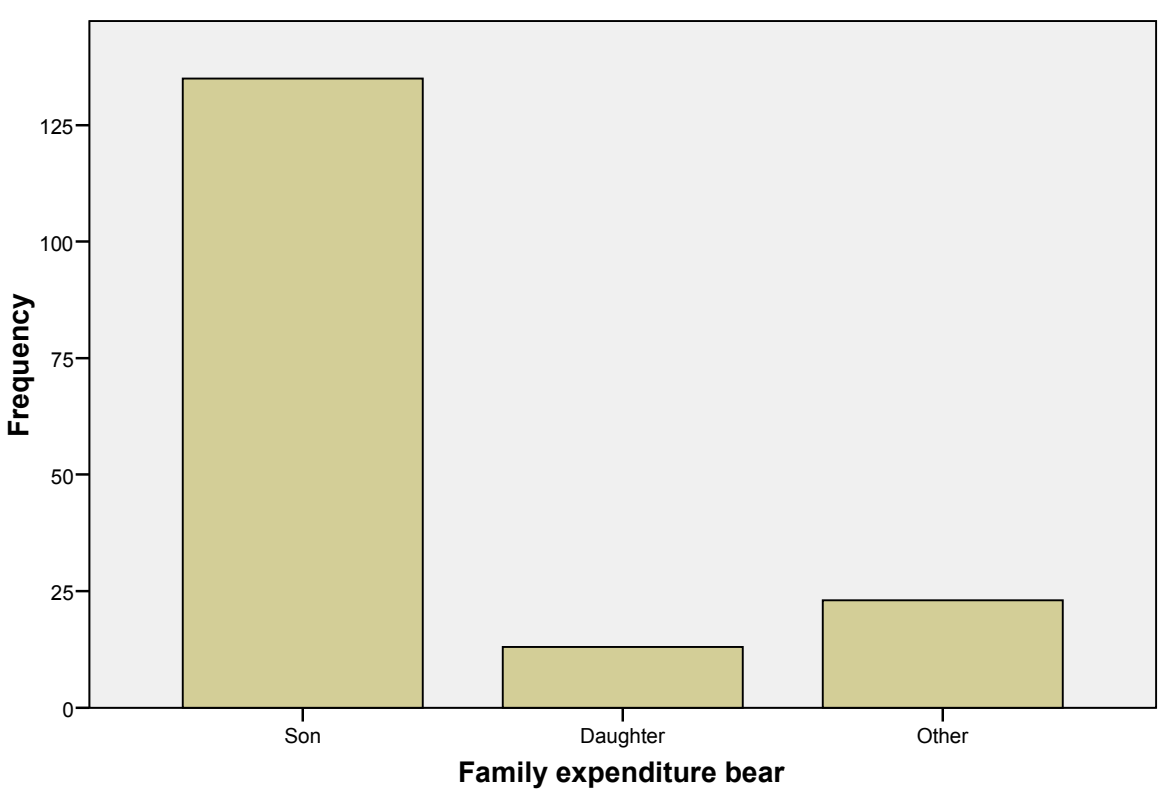

Figure 1. Bar diagram of family expenditure bearing in ageing people.

Table 2. Frequency of health care most of older people.

\begin{tabular}{llll}
\hline Variable & Frequency & Percent & Cumulative Percent \\
\hline Son & 90 & 53.6 & 52.6 \\
Daughter & 67 & 39.2 & 91.8 \\
No one & 14 & 8.2 & 100 \\
Total & 171 & 100 & - \\
\hline
\end{tabular}

\section{Health care most}

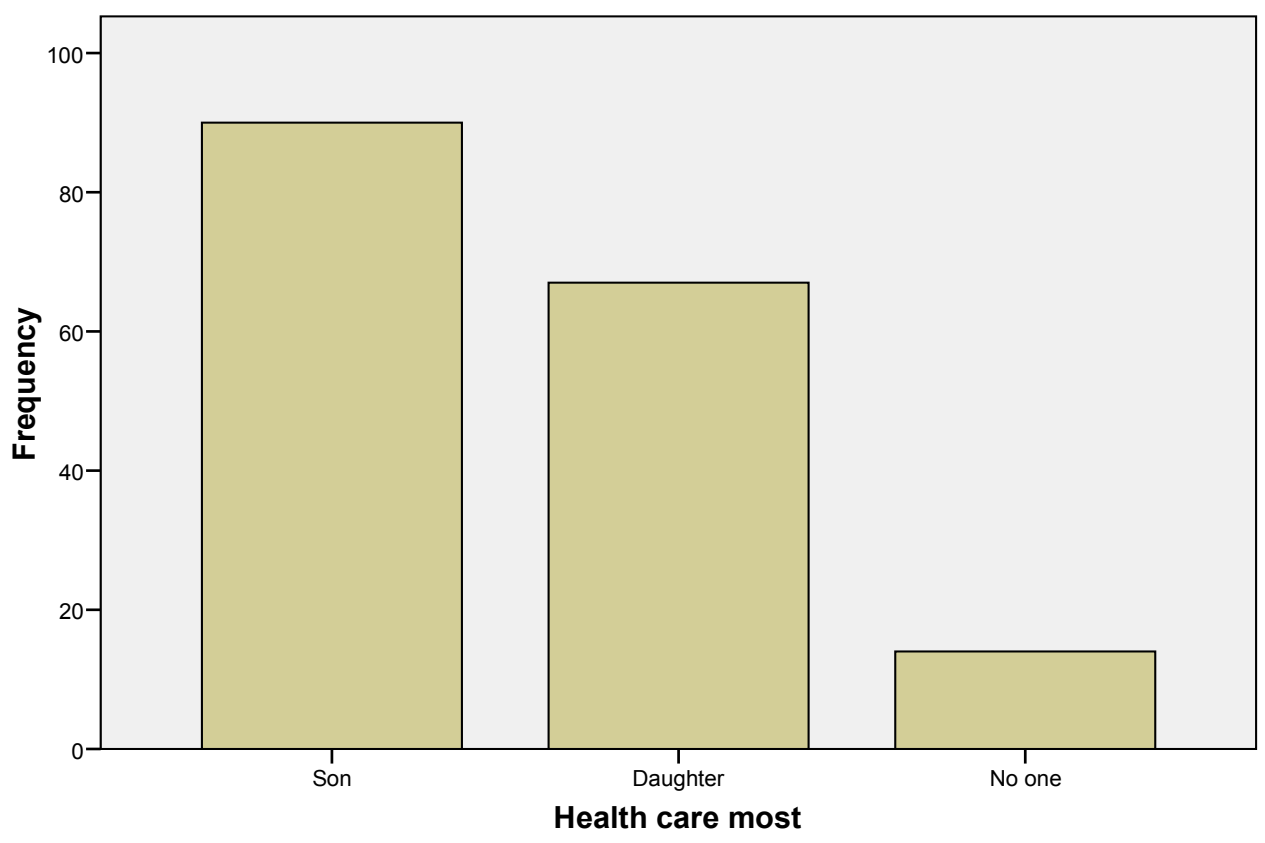

Figure 2. Bar diagram of health care most of older people in Bangladesh.

From the table, $52.6 \%$ ageing people's health are cared by their son, $39.2 \%$ by their daughters and $8.2 \%$ by others. This indicates that ageing people's health mostly cared by their son. 
Table 3. Treatment cost distribution of ageing people.

\begin{tabular}{llll}
\hline Treatment cost & Frequency & Percent & Cumulative Percent \\
\hline $0-2000$ & 103 & 60.2 & 60.2 \\
$2000-4000$ & 39 & 22.8 & 83.0 \\
$4000-6000$ & 24 & 14.0 & 97.1 \\
$6000-8000$ & 3 & 1.8 & 98.8 \\
Above 8000 & 2 & 1.2 & 100 \\
Total & 171 & 100 & - \\
\hline
\end{tabular}

\section{Treatment Cost}

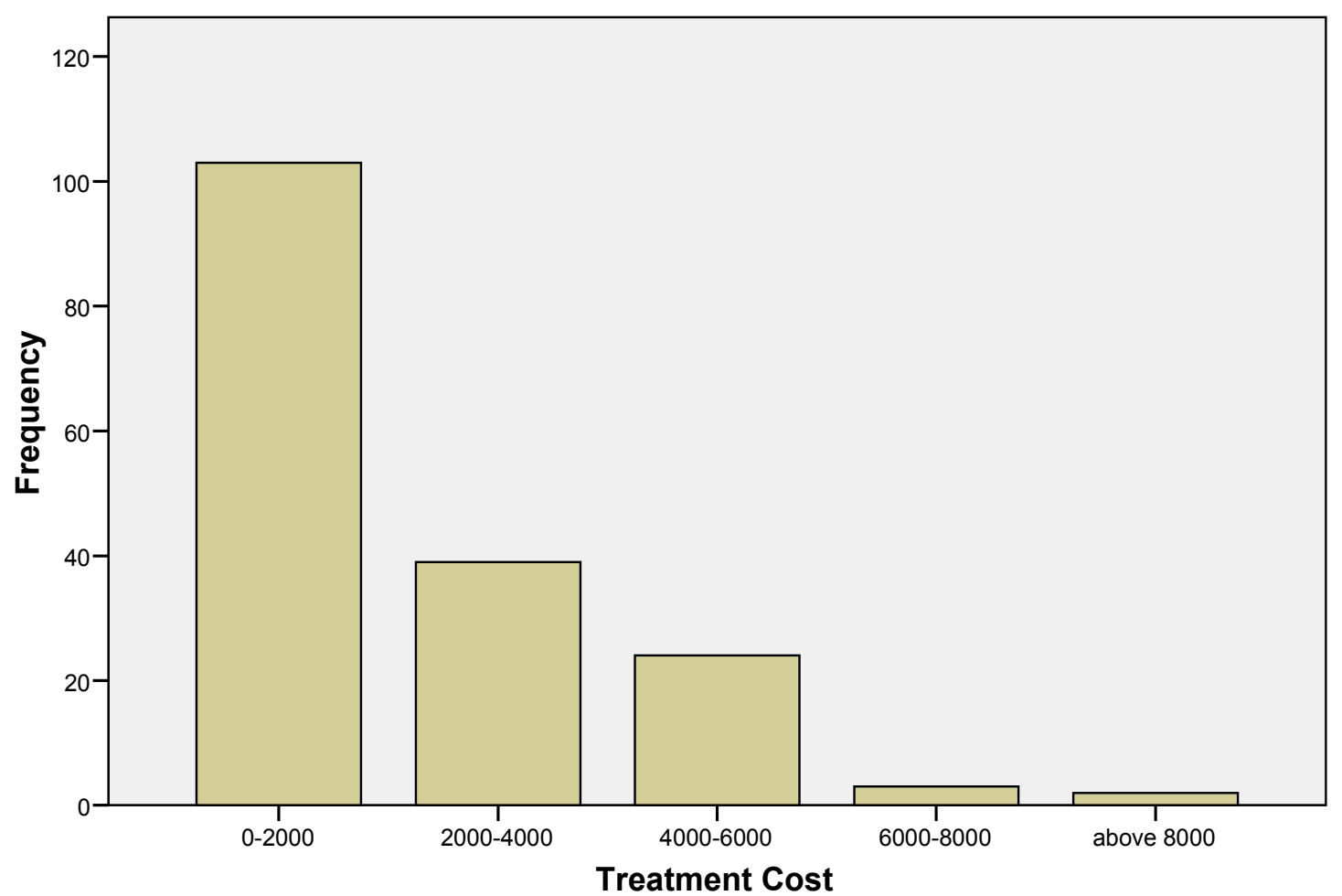

Figure 3. Bar diagram of treatment cost of ageing people.

From the frequency distribution we see that $60.2 \%$ ageing people's treatment cost lies in (000-2000) taka, $22.8 \%$ lies in (2000-4000) taka, 14\% lies in (4000-6000) taka, 1.8\% lies in
(6000-8000) taka and $1.2 \%$ lies in above 8000 taka. This indicates that maximum ageing people's treatment cost lies in (000-2000) taka.

Table 4. Ageing people's disease most suffer in Bangladesh.

\begin{tabular}{llll}
\hline Disease & Frequency & Percent & Cumulative Percent \\
\hline Weakness & 15 & 8.8 & 8.8 \\
Blood Pressure & 35 & 20.5 & 29.2 \\
Diabetics & 57 & 33.3 & 62.6 \\
Heart disease & 34 & 19.9 & 82.5 \\
Arthritis & 10 & 5.8 & 88.3 \\
Bone disease & 11 & 6.4 & 94.7 \\
Asphyxia & 7 & 4.1 & 98.8 \\
None & 2 & 1.2 & 100 \\
Total & 171 & 100 & - \\
\hline
\end{tabular}




\section{Disease have most}

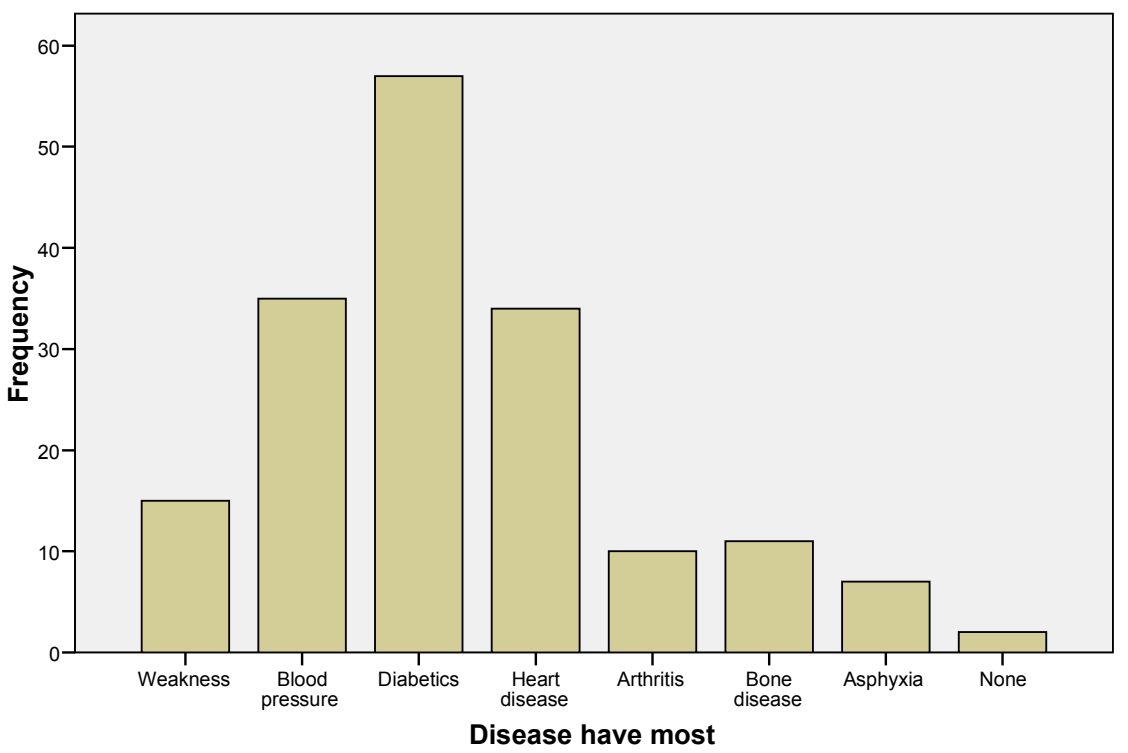

Figure 4. Diagram of ageing people's disease most suffer in Bangladesh.

The table 4 shows that $33.3 \%$ ageing people have diabetics, $20.5 \%$ have blood pressure, $19.9 \%$ have heart disease and rest of them has other diseases like as weakness, arthritis, bone disease, asphyxia. So we can say that most ageing people have the problem of diabetics.

\section{Visit to doctor for treatment}

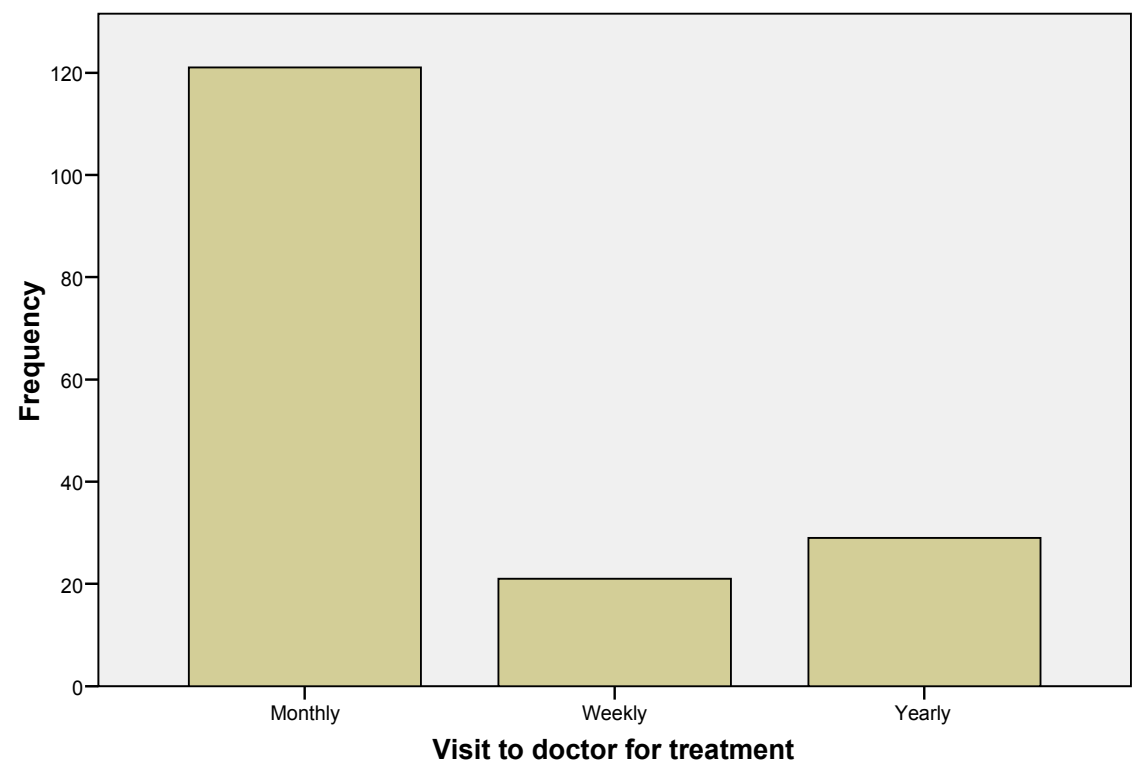

Figure 5. Diagram of ageing people's visit to doctors.

Table 5. Percentage of doctor's visit of older people.

\begin{tabular}{llll}
\hline Doctor's visit & Frequency & Percent & Cumulative Percent \\
\hline Monthly & 121 & 70.8 & 70.8 \\
Weekly & 21 & 12.3 & 83.0 \\
Yearly & 29 & 17 & 100 \\
Total & 171 & 100 & - \\
\hline
\end{tabular}

So, there are $70.8 \%$ ageing people who visit to doctor monthly, $17 \%$ visit to doctor yearly, $12.3 \%$ visit to doctor weekly and there are no aging people who visit to doctor daily for their treatment. Which indicates that most elderly people visit to doctor monthly and less visit to doctor daily for their treatment.

\subsection{Correlation}

Family expenditure bears and satisfied with treatment 
Table 6. Correalation table between family expenditure bear and satisfied with treatment of older people.

\begin{tabular}{llll}
\hline & & family expenditure bear & Satisfied with treatment \\
\hline \multirow{3}{*}{ family expenditure bear } & Person Correlation & 1 & 0.242 \\
& Sig (2-tailed) & & .001 \\
& $\mathrm{~N}$ & 171 & 171 \\
& Person Correlation & 0.242 & 1 \\
satisfied with treatment & Sig (2-tailed) & .001 & 171 \\
\hline
\end{tabular}

This table shows, The Pearson correlation $r=0.242$. So the relation between family expenditure bear and satisfied with treatment of ageing people is positive but weak.

Table 7. Chi-square table for association of family expenditure bears and satisfied with treatment.

\begin{tabular}{llll}
\hline & Value & df & Asymp. Sig (2-sided) \\
\hline Person Chi-square & 10.122 & 2 & .006 \\
Likelihood Ratio & 9.199 & 2 & .010 \\
Linear-by-Linear Association & 9.918 & 1 & .002 \\
N of Valid case & 171 & & \\
\hline
\end{tabular}

This table shows, The Pearson correlation $r=0.242$. So the relation between family expenditure bear and satisfied with treatment of ageing people is positive but weak.

Health care most and satisfied with treatment.

Table 8. Correalation table between health care most and satisfied with treatment.

\begin{tabular}{lccc}
\hline & Health care most & Satisfied with treatment & .120 \\
\hline & Person Correlation & 1 & .118 \\
Health care most & Sig (2-tailed) & & 171 \\
& $\mathrm{~N}$ & .120 & 1 \\
satisfied with treatment & Person Correlation & .118 & 171 \\
& Sig (2-tailed) & 171 & 171 \\
\hline
\end{tabular}

Here Pearson Correlation $r=0.120$. Therefore, the relation between health care most and satisfied with treatment is positive but weak.

Table 9. Chi-square table.

\begin{tabular}{llll}
\hline & Value & df & Asymp. Sig (2-sided) \\
\hline Person Chi-square & 2.472 & 2 & .291 \\
Likelihood Ratio & 2.427 & 2 & .297 \\
Linear-by-Linear Association & 2.454 & 1 & .117 \\
N of Valid case & 171 & & \\
\hline
\end{tabular}

This Chi-square table shows, health care most and satisfied with treatment of ageing people are not statistically significant. Visit to doctor for treatment and satisfied with treatment:

Table 10. Correlation table between visit to doctor for treatment and satisfied with treatment.

\begin{tabular}{llll}
\hline & & Visit to doctor & Satisfied with treatment \\
\hline \multirow{3}{*}{ Visit to doctor } & Person Correlation & 1 & 0.028 \\
& Sig (2-tailed) & & .713 \\
& $\mathrm{~N}$ & 171 & 171 \\
satisfied with treatment & Person Correlation & 0.028 & 1 \\
& Sig (2-tailed) & .713 & 171 \\
\hline
\end{tabular}

Here Pearson Correlation $\mathrm{r}=0.028$. Therefore, the relation between visit to doctor for treatment and satisfied with treatment is positive but weak. 
Table 11. Chi-square table.

\begin{tabular}{llll}
\hline & Value & df & Asymp. Sig (2-sided) \\
\hline Person Chi-square & 4.358 & 2 & .113 \\
Likelihood Ratio & 3.935 & 2 & .140 \\
Linear-by-Linear Association & .136 & 1 & .712 \\
N of Valid case & 171 & & \\
\hline
\end{tabular}

\subsection{Logistic Regression Analysis}

Table 12. Logistic Regression Analysis table.

\begin{tabular}{|c|c|c|c|c|c|}
\hline & B & S. E & df & Sig. & $\operatorname{Exp}(B)$ \\
\hline Family expenditure bear & .694 & .269 & 1 & .010 & 2.002 \\
\hline Health care most & .018 & .318 & 1 & .956 & 1.018 \\
\hline Visiting doctor & .116 & .236 & 1 & .623 & 1.123 \\
\hline Constant & -2.424 & .777 & 1 & .002 & .089 \\
\hline
\end{tabular}

From the logistic regression line we can see that the intercept is -2.424 and

i. If we increase one unit of family expenditure bear (son) then the satisfaction level (yes) will increase 0.694 unit.

ii. If we increase one unit of health care most (son) then the satisfaction level (yes) will increase 0.018 unit and

iii. If we increase one unit of visiting doctor (daily) then the satisfaction level (yes) will increase 0.116 unit.

\section{Data Availability Statement}

We used primary data using questionnaire method and collected information from 171 respondents and analysis data by using SPSS software. This qualitative data used to support the findings of this study are included within the article.

\section{Conclusion}

On the basis of the findings of the present study the following recommendation were made for the health status of ageing population in Bangladesh. The main importance should be given on the health status of ageing (aged $\geq 60$ years) population in Bangladesh. Create awareness on health status of ageing people to the all people of Bangladesh. Government should create a strict law for the betterment of ageing people and increase their budget. Union or upazilla may arrange seminar or workshop for the ageing people to know the importance of health care of older people in Bangladesh. Government should arrange monthly checkup program for ageing people in all upazilla of Bangladesh. Proper training for the health professionals should be organized to provide care for ageing people. Sustainable policies on long-term and palliative care should be designed. Various health organisation and NGO should develop agefriendly services and settings for aged people. We should arrange programs to prevent and deal with elder abuse. Health and social programs should be arranged targeted at vulnerable groups such as those who live alone and rural population or who suffer from chronic or relapsing mental or physical illness. Government should do adequate house planning for aged people through supportive housing policy. From the entire study we can conclude that not only government but also we should increase awareness among common people.

\section{References}

[1] US Census Bureau. Summary demographic data for Bangladesh, 2000. Available from: http://www.census.gov/cgi-bin/ipc/idsum?

[2] Haque MM, Uddin A K M M, Naser MA, Khan MZH, Roy SK, Arafat Y. Health and Nutritional Status of aged people. Chattagram Maa-O-Shishu Hospital Medical College Journal. September 2014; Volume 13, Issue 3: 30-34.

[3] Garcia LMR, Navarrro JMR. The Impact of Quality of Life on the Health of Older People from a Multidimensional Perspective. Hindawi. 2018; Volume 2018, Article ID 4086294: 7 pages.

[4] Yeung WJ, Cheung AK. Living alone: One-person households in Asia. Demographic Research. 3 June 2015; Volume 32, Article 40: 1099-1112.

[5] UNFPA. Population and reproductive health country profiles: Bangladesh, 2003. Available from: http://www.unfpa.org/profile/bangladesh.cfm.

[6] World Population Ageing 2013, Department of Economic and Social Affairs Population Division, United Nations, New York, 2013. Available from: http://www.un.org/en/development/desa/population/publicatio ns/pdf/ageing/World Population Ageing Report 2013.pdf.

[7] Barikdar A, Ahmed T, Lasker SP. The Situation of the Elderly in Bangladesh. Bangladesh Journal of Bioethics 2016; 7 (1): 27-36.

[8] Available from: www.bbs.gov.bd.

[9] Uddin M Taj, K; Chowdhury MAI, Nazrul Islam M and Uddin Baher G. Status of elderly people of Bangladesh: health perspective. Proc. Pakistan Acad. Sci. 2010; 47 (3): 181-189.

[10] Basch PF. Environment, development and health. In: Textbook of international health. $2^{\text {nd }}$ edition. New York: Oxford University Press; 1999. P. 235-94. 
[11] Olli Nummela, Tommi S., Ossi R., Antti K., Antti U (2008), "Social participation, trust and self-rated health: A study among ageing people in urban, semi-urban and rural settings", Health \& Place, Volume 14, Issue 2, Pages 243-253.

[12] Su Hyun Kim (2009), "Older people's expectations regarding ageing, health-promoting behaviour and health status", Wiley Online Library, Volume65, Issue1, Pages 84-91.

[13] Meindert H., and et al. (2011), "Ageing and health status in adults with intellectual disabilities: Results of the European POMONA II study", Journal of Intellectual \& Developmental Disability Volume 36, 2011 - Issue 1, Pages 49-60.
[14] Nummela, O., Sulander, T., Rahkonen, O. et al. Associations of self-rated health with different forms of leisure activities among ageing people. Int J Public Health53, 227-235 (2008). https://doi.org/10.1007/s00038-008-6117-2.

[15] Munsur, Ahmed Mohammad; Tareque, Ismail; and Rahman, K. M. Mustafizur (2010), "Determinants of Living Arrangements, Health Status and Abuse among Elderly Women: A Study of Rural Naogaon District, Bangladesh". Journal of International Women's Studies, 11 (4), 162-176. 